\title{
Morfologia da glândula pineal de gambás (Didelphis sp)
}

Celina Almeida Furlanetto MANÇANARES ${ }^{1}$ Irvênia Luiza de Santis PRADA² Ana Flávia de CARVALHO ${ }^{1}$ Maria Angélica MIGLINO² João Flávio Panattoni MARTINS 1

Carlos Eduardo AMBRÓSIO1,2

Correspondência para:

${ }^{1}$ Celina Almeida Furlanetto Mançanares Centro Universitário da Fundação de Ensino Octávio Bastos

Av. Doutor Octávio Bastos s/n Jardim Nova São João

13874-148 - São João da Boa Vista-SP

e-mail: celina@unifeob.edu.br

Recebido para publicação: 28/02/2005 Aprovado para publicação: 27/03/2007
1 - Departamento de Ciências Morfológicas, Centro Universitário da Fundação de Ensino Octávio Bastos (UNIFEOB), São João da Boa Vista - SP

2 - Departamento de Cirurgia, Faculdade de Medicina Veterinária e Zootecnia Universidade de São Paulo, São Paulo - SP

\section{Resumo}

Palavras-chave: Gambá.

Glândula pineal.

A glândula pineal deve ser analisada e estudada em animais da fauna Morfologia animal. brasileira, para que dados da pesquisa básica possam ser aplicados em novas técnicas de manejo reprodutivo destes animais, inclusive em cativeiro, face à íntima relação deste órgão fotorreceptor com o ciclo reprodutivo. Para este estudo, foram utilizados 10 gambás (Didelphis sp), provenientes do Departamento de Anatomia da USP e da UNIFEOB, já mortos e fixados. Nenhum animal foi submetido a situações de dor/sofrimento e ao sacrifício de sua vida. A glândula pineal foi encontrada em todos animais estudados e apresentou-se com diminutas dimensões, não sendo possível, portanto descreverlhe características macroscópicas. Através da análise microscópica pudemos localizar a glândula no espaço correspondente ao plano mediano, em relação ao encéfalo, rostral e dorsalmente aos colículos rostrais, ventralmente aos hemisférios cerebrais e caudalmente à comissura habenular. Consiste de uma evaginação do teto do diencéfalo e mostra-se em forma de " $U$ " invertido. Comparativamente a características de glândulas pineais de outras espécies animais, a do Didelphis genus, que estudamos, revela peculiaridades tanto em relação ao seu tamanho, apenas perceptível microscopicamente, quanto ao fato de apresentar células semelhantes às secretoras, dispersas também em áreas vizinhas. Tais peculiaridades motivam reflexões sobre o papel funcional da glândula, na espécie considerada.

\section{Introdução}

A glândula pineal é uma glândula endócrina cujas secreções são influenciadas pelos períodos de luz/escuridão do dia. Ela é uma projeção mediana em forma de cone, que parte do diencéfalo, com um recesso do terceiro ventrículo ${ }^{1}$. Hofer, Merker e Oksche $^{2}$ referem que, no Didelphis sp, uma considerável porção do parênquima pineal localiza-se dentro da região da comissura habenular, em posição subependimal, subpial e interfascicular.

A glândula pineal, apesar dos estudos intensivos, a seu respeito, nas últimas décadas, continua desconhecida em muitos de seus aspectos, particularmente em alguns grupos de animais, como é no caso dos marsupiais.
A glândula pineal deve ser analisada e estudada em animais da fauna brasileira, para que possamos, através de dados obtidos nestas pesquisas básicas, aplicar novas técnicas de manejo reprodutivo destes animais inclusive em cativeiro, tendo em vista a íntima relação deste órgão fotorreceptor com ciclos circadianos e ciclo reprodutivo. Este projeto teve por objetivo a caracterização morfológica da glândula pineal de Didelphis $s p$ pela análise macroscópica, microscopia de luz e microscopia eletrônica de varredura.

\section{Material e Método}

Para a realização desta pesquisa foram coletados 10 encéfalos de gambás (Didelphis $s p$ ) adultos, sendo quatro machos e seis 
fêmeas. Destes 10 animais, três foram destinados ao estudo macroscópico, cinco ao estudo pela microscopia de luz e dois para a Microscopia eletrônica de varredura. Estes animais, já mortos, encontravam-se fixados no Setor de Anatomia da FMVZ/ USP e do Departamento de Anatomia da UNIFEOB, oito com formaldeído a 10\% e dois fixados por glutaraldeído a $4 \%$. Estes animais já foram utilizados em outras pesquisas e encontravam-se acondicionados em cubas. Para esta pesquisa, nenhum animal foi submetido a situações de dor/sofrimento e ortotanásia.

\section{COLHEITA E ANÁLISE MACROSCÓPICA}

Oito animais fixados com formaldeído a $10 \%$ e injetados com látex vermelho (para artérias) e látex azul (para veias) foram utilizados para análise macroscópica. Os encéfalos foram retirados e foi realizada uma incisão da pele, no plano mediano, desde a região supra-orbitária até a região occipital. A musculatura ao redor da calota craniana foi removida, expondose a superfície óssea que, com auxilio de costótomo, foi seccionada em fragmentos, o que possibilitou o isolamento dos encéfalos mediante secção dos nervos cranianos. As peças foram devidamente etiquetadas com os números correspondentes aos animais e data de colheita. Os encéfalos foram seccionados manualmente na fissura mediana, expondo-se a pineal. A região anatômica correspondente à glândula pineal foi fotografada. A documentação fotográfica macroscópica da glândula pineal foi feita através de uma câmara digital Sony Mavica 3.2 MP.

\section{PREPARAÇÃO DAS AMOSTRAS PARA OBSERVAÇÃO AO MICROSCÓPIO DE LUZ}

As glândulas foram retiradas com uma zona de segurança de tecido nervoso para posterior inclusão rotineira em similar parafina (Histosec-Merckâ) e historesina (resina glicol metacrilato historesin, 702218500) fabricado por LEICA Instruments da Alemanha. As lâminas que receberam os cortes de historesina foram previamente preparadas com 50\% de cola branca e água. Foram obtidos cortes com espessura de 5 micrômetros para o material incluido em parafina e com 2 micrômetros para os em resina glicolmetacrilato. A documentação fotográfica microscópica da glândula pineal foi feita através do fotomicroscópio Nikon Eclipse E-400

\section{PROCESSAMENTO EM HISTOSEC $^{\circledR}$ (MERCK)}

As glândulas pineais de gambás foram pós-fixadas em solução fixadora de paraformaldeído a $4 \%$ em PBS (Dulbecco's phosfate buffer saline-DPBS, Gibco Co., USA) posteriormente o material foi desidratado em uma série de etanol em concentrações crescentes (de 70 a 100\%) e diafanizado em xilol, seguido-se inclusão em Histosec $^{\circledR 3}$.

\section{PROCESSAMENTO EM HISTORESINA (HYDROXYETHYL METHACRYLATE-HISTORESIN, LKB 218-500, SWEDEN)}

Para inclusão em metacrilato, as amostras também foram pós-fixadas em paraformoldeído a $4 \%$ em PBS, o material foi lavado em PBS, desidratado em etanol (concentrações crescentes de 50 a $100 \%$ ) e finalmente infiltrado na proporção de 1:1 em solução infiltradora $(50 \mathrm{ml}$ de resina básica [glicol-metacrilato] e $0,5 \mathrm{ml}$ de ativador [peróxido de benzoila] /álcool 95\% durante 2 horas e deixado para polimerizar em uma mistura de resina $(15 \mathrm{ml}$ de solução infiltradora e $1 \mathrm{ml}$ de endurecedor, derivado do ácido barbitúrico-DMSO) em estufa a $37{ }^{\circ} \mathrm{C}$, overnight). Após feitos os cortes o material foi corado por H\&E, hematoxilinaeosina-floxina, azul de Toluidina ${ }^{3}$ e Picrossírius ${ }^{4}$. 
PROCESSAMENTO PARA MICROSCOPIA ELETRÔNICA DE VARREDURA

O material fixado em glutaraldeído a $2,5 \%$ foi lavado em tampão fosfato por 3 vezes, colocado posteriormente em solução de ácido tânico a 2\% durante duas horas à temperatura ambiente e lavado em tampão fosfato. Em seguida, o material foi pósfixado em solução de tetróxido de Ósmio a $2 \%$ durante 90 minutos. As amostras foram lavadas em tampão fosfato e, posteriormente, também lavadas em água destilada. $\mathrm{O}$ material ficou em imersão em acido tânico por meia hora e depois foi lavado em água destilada. As amostras passaram pelo processo de desidratação em álcool etílico em concentrações de 50\% (2x -15 minutos); $70 \%$ (15 minutos); 80\% (15 minutos); $90 \%$ ( $2 \mathrm{x}-15$ minutos) e $100 \%$ ( $4 \mathrm{x}-15$ minutos), posteriormente foi feita a secagem em aparelho de ponto crítico Balzers, CPD-030, utilizando $\mathrm{CO}_{2}$ líquido. Os fragmentos foram montados em bases metálicas de alumínio (stubs) com cemento de carbono e cobertas com ouro $(\mathrm{Au})$ através do aparelho Iom Sputter Balzer SCD - 040 e foram analisados em microscópio eletrônico de varredura Zeiss Leo 435 VP do Setor de Anatomia dos Animais Domésticos e Silvestres - USP.

\section{Resultados}

A nomenclatura utilizada foi referida conforme International Commitee on Veterinary Gross Anatomical Nomenclature ${ }^{5,6}$.

A glândula pineal de gambá (Didelphis $s p)$, em estudos preliminares apresentou-se microscópica, impedindo que avaliações de peso e medidas pudessem ser efetuados.

O encéfalo de Didelphis sp foi abordado no início dorsalmente sendo notada ausência de circunvoluções no cortex cérebral, com o bulbo olfatório extremamente desenvolvido. Afastando-se os lobos occipitais, do cerebelo, visualizouse a região onde se situava a glândula pineal que era provida de muitos vasos sanguíneos
(Figura 1 ).

A glândula pineal foi encontrada em relação ao plano mediano, próxima à comissura habenular e rostralmente aos colículos rostrais (Figura 1).

Quanto à observação microscópica, foi possível visualizar a glândula pineal em todos os animais analisados. Após a análise dos cortes histológicos em diferentes colorações, pudemos observar a presença da glândula pineal em correspondência ao plano mediano, rostralmente aos dois colículos rostrais, representando diminuta evaginação do teto do diencéfalo. Seu formato característico assemelhou-se ao da letra " $U$ " invertida, particularmente evidenciado em cortes sagitais medianos (Figura 2)

Observamos o corpo pineal, em íntima relação com a base da glândula, que se inseria no teto do diencéfalo. A comissura habenular foi identificada em relação à porção superior do corpo pineal. O recesso pineal era evidente e revestido por epitélio cilíndrico baixo ciliado. O órgão subcomissural apresentou-se ascendente à curvatura que divide o recesso pineal do recesso intercomissural (Figura 2).

Quando foram observados cortes seqüenciais, observou-se que na porção mediana existiam células muito semelhantes aos pinealócitos na base do órgão subcomissural e também permeando a estrutura dos colículos rostrais. Pudemos notar que estas células do corpo pineal (pinealócitos) possuíam núcleos arredondados e grandes com cromatina evidente e citoplasma pouco aparente. As células encontradas na base do órgão subcomissural (colículos rostrais) possuíam o mesmo aspecto, porém com citoplasma mais evidente (Figura 2).

Áreas com fibras nervosas eram evidentes principalmente no órgão subcomissural. Nervos com fibras mielínicas foram observados em abundância nesta região.

Todas as porções do corpo pineal e do órgão subcomissural apresentaram grande quantidade de vasos. Foram 


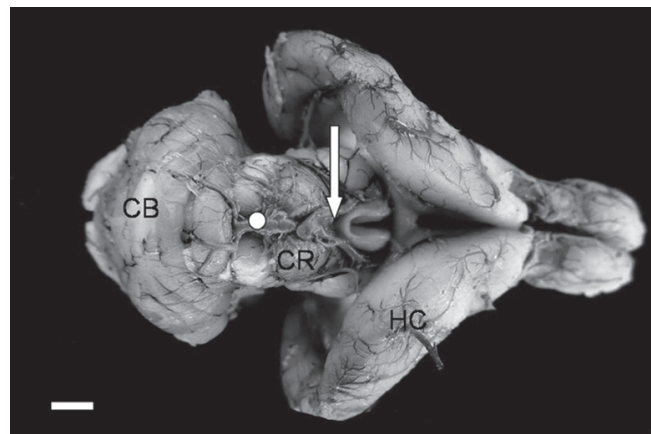

Figura 1 - Fotografia de encéfalo de Didelphis sp, em vista dorsal, com afastamento lateral dos hemisférios cerebrais $(\mathrm{HC})$. Cerebelo $(\mathrm{CB})$; comissura habenular e localização da glândula pineal (seta); rede vascular (ponto branco); colículos rostrais (CR). Técnica de injeção de látex e fixação - azul, veias e em vermelho, artérias. Barra $1 \mathrm{~cm}$

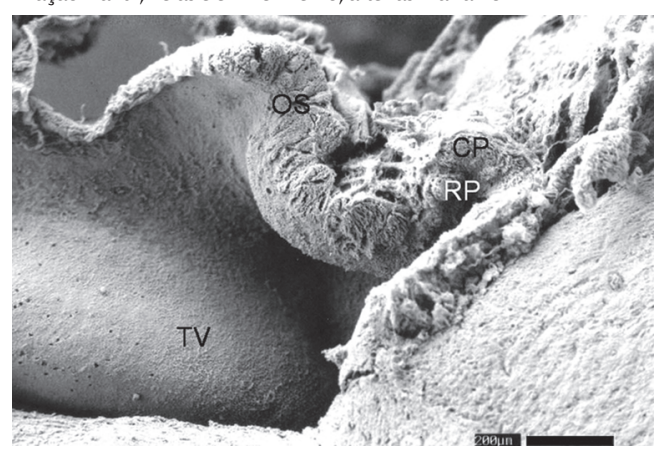

Figura 3 - Eletromicrografias da glândula pineal de Didelphis sp. Notar o aspecto da glândula pineal, vista ventral. CP - corpo pineal; OS órgão subcomissural; RP - recesso pineal; TV - terceiro ventrículo. Barra $=200 \mathrm{~mm}$

encontrados mastócitos na região periférica externa dos vasos sanguíneos justapostos ao endotélio. Não pudemos notar na glândula pineal de Didelphis sp. uma cápsula de tecido conjuntivo evidente, sendo caracterizada por um endotélio simples.

À microscopia eletrônica de varredura pudemos notar tridimensionalmente os aspectos da superfície pineal em formato de "U" invertido característico (Figura 3).

À medida que se afastavam do plano mediano, a figura de " $U$ " invertido da glândula pineal deixava progressivamente de ser caracterizada identificando-se então sua estrutura em faixa alongada (Figura 3).

No epitélio do recesso pineal pudemos observar presença de cílios.

\section{Discussão}

Os aspectos microscópicos da glândula pineal de Didelphis sp são muito

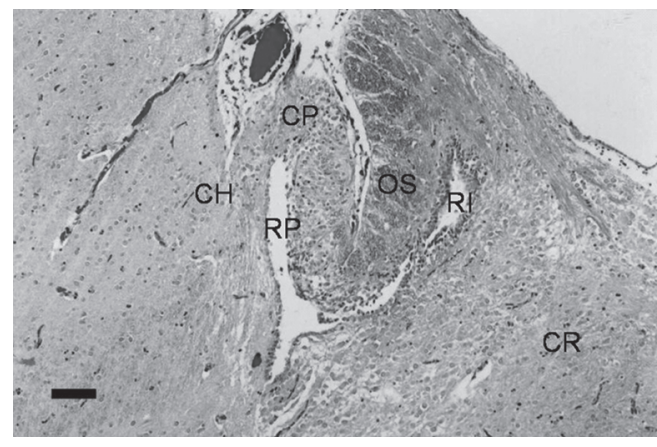

Figura 2-Fotomicrografia da glândula pineal de Didelphis sp, em formato de " $U$ " invertido. $\mathrm{CH}$-comissura habenular; $\mathrm{CP}$ - corpo pineal; $\mathrm{RP}$ recesso pineal; $\mathrm{OS}$ - órgão subcomissural; $\mathrm{RI}$ - recesso intercomissural; CR - colículo rostral. Fotomicrografia - Tricromo de Masson, Barra $=90 \mathrm{~mm}$

interessantes e importantes tendo em vista seu tamanho microscópico.

Diferentemente do "formato de pinha", da glândula pineal humana segundo Dyce, Sack e Wensing ${ }^{7}$, outras formas tem sido identificadas em varias espécies como no caso deste trabalho sobre Didelphis sp, em que pudemos observar uma forma de " $U$ " invertido, cujo arranjo final só pôde ser elucidado através de Microscopia Eletrônica de Varredura.

Ao iniciarmos os nossos estudos nos indagamos sobre a afirmação de Schaffe, Symington e Bryce ${ }^{8}$, de que todos animais possuíam pineal, exceto o anfioxo. Quando decidimos averiguar sobre a glândula pineal de Didelphis sp, tanto o D. virginiana quanto o Didelphis albiventris, esperamos encontrar a glândula evidente macroscopicamente. Entretanto, neste trabalho, foi identificado a glândula pineal apenas microscopicamente sendo, portanto, difícil comparar esta glândula com achados macroscópicos de outros autores, em outras espécies. Vollrath ${ }^{9}$ também descreveu que os crocodilianos, edentatas e sirenios não possuíam um órgão pineal definido. No Didelphis, a caracterização do corpo pineal foi trabalhosa pois os pinealócitos também pareciam estar presentes na região dos colículos rostrais, sugerindo ser esta pineal, uma glândula com parte do parênquima disseminada.

Foi encontrada a glândula pineal de Didelphis sp em correspondência ao plano mediano entre os dois hemisférios cerebrais rostralmente aos colículos rostrais, apensa ao 
teto do diencéfalo, conforme referem Gartner e Hiatt ${ }^{1}$ e Vollrath ${ }^{10}$.

A estrutura pineal de Didelphis sp, por ser microscópica, era muito peculiar, com formato único em "U" invertido, o que difere dos achados em roedores que possuem, segundo Branco et al. ${ }^{11} \mathrm{e} \mathrm{Vollrath}^{10}$, formato de bastão e, em serpentes, que segundo Holanda-Barros ${ }^{12}$, tem formato ovóide. Segundo Silvino et al. ${ }^{13}$, esta estrutura em roedores (cutia) era desprovida de lúmen, o que no Didelphis também não foi observado.

Já em búfalos e cães, Carvalho ${ }^{14} \mathrm{e}$ Gomes ${ }^{15}$ notaram que essa glândula mostrava-se macroscopicamente com formato de "amendoim" e globosa, respectivamente, com grande variação de formato em relação ao Didelphis, confirmando os dados de dados de Jordan ${ }^{16}$ que trabalhou com marsupiais.

As diferentes classificações propostas por Blin e Maurin ${ }^{17}$ e Oksche ${ }^{18}$ não satisfizeram os meios científicos e posteriormente em 1981, Vollrath ${ }^{10}$ classificou a glândula pineal com maior rigor. Pudemos comparar os nossos achados com informações exaradas por Blin e Maurin ${ }^{17}$, classificando a glândula desses animais como pós-calosa. Pela classificação de Oksche ${ }^{18}$, como alongada e, pela de Vollrath ${ }^{10}$, como do tipo A.

Histologicamente observou-se que a glândula pineal de Didephis sp possuía uma delgada camada de mesotélio disposta envolvendo fina rede de fibras colágenas que se encontram em contato com o órgão pineal. Este fino tecido conjuntivo supre, através de seus vasos e nervos, a glândula pineal, porém não há divisão distinta da glândula em lóbulos, como o descrito por Lesson e Lesson ${ }^{19}$.

Os achados histológicos em Didelphis sp assemelharam-se aos de Branco et al. ${ }^{11}$, Carvalho ${ }^{14}$, Gomes ${ }^{15}$, Holanda-Barros ${ }^{12}$ Jordan ${ }^{16} \mathrm{e}$ Moller e Baeres ${ }^{20}$. No parênquima encontramos pinealócitos, além de células gliais, vasos nervosos, nervos e algumas características especiais que serão discutidas a seguir.
Os pinealócitos são o tipo celular predominante com citoplasma basófilo e núcleos arredondados contendo, na maioria das vezes, mais de dois nucléolos, organizados em cordões. Esses achados assemelham-se aos encontrados por Ross, Reith e Romrell ${ }^{21}$.

Todas as características morfológicas das células estudadas foram compatíveis com a identificação de pinealócitos, o que não dispensa a efetuação de procedimentos de imunohistoquímica com marcadores específicos para essas células, o que pretendemos realizar em etapas futuras. A aplicação técnica será importante principalmente na elucidação das áreas expandidas (órgão subcomissural e colículos rostrais) além do corpo pineal, onde essas células também se apresentaram. Aliás, o fato de encontrarmos presença de células (sugestivas de serem pinealócitos) em áreas expandidas alem do corpo pineal (órgão subcomissural e colículos rostrais) encontra ressonância no exarado por Hofer, Merker e Oksche ${ }^{2}$, para quem, no Didelphis uma considerável porção do parênquima pineal localiza-se dentro da região da comissura habenular, em posição subependimal, subpial e interfascicular.

Segundo Tulsi ${ }^{22}$, estudos em microscopia eletrônica de varredura mostraram que o recesso pineal de Trichourus vulpeca possuía áreas ciliadas e não ciliadas, inferindo a este respeito que algumas regiões são mais secretoras que outras. Apesar de nossos estudos não terem sido baseados apenas no recesso pineal, pudemos observar a presença de cílios na região do recesso pineal compatíveis com os achados de Samarasingle e Delahunt ${ }^{23}$.

Finalmente, diante destas comparações e buscando complementar informações inerentes à morfologia da pineal de marsupiais, esperamos ter, com este trabalho, dado a nossa contribuição a um assunto tão vasto e tão questionado. Portanto, outros projetos serão necessários para melhor elucidação das estruturas da glândula pineal de Didelphis sp, principalmente para se averiguar a difusão de pinealócitos para áreas 
vizinhas (órgão subcomissural e colículos rostrais) ao corpo da glândula.

\section{Conclusões}

Do que foi exposto, julgamos válidas as seguintes conclusões:

A glândula pineal estava presente em todos os animais analisados, porém não pode ser visualizada macroscopicamente devido ao seu diminuto tamanho. A glândula pineal localizou-se em correspondência ao plano mediano, entre os dois hemisférios cerebrais, rostralmente aos colículos rostrais e caudalmente à comissura habenular. Microscopicamente apresentou-se em formato de "U" invertido e apresentou células semelhantes aos pinealócitos dispersos em áreas vizinhas (orgão subcomissural e colículos rostrais) ao corpo da glândula. A glândula pineal do Didelphis sp pôde ser assim classificada: como sendo do tipo A, alongada e pós calosa.

\title{
Morphology of the pineal gland in opossum (Didelphis sp)
}

\begin{abstract}
The pineal gland must to be analyzed and studied in animals of the Brazilian fauna, to apply the data obtained in the basic research of new techniques at reproductive handling of these animals, including in captivity, in view of the close relation between this photoreceptor organ with the circadian and reproductive cycle. For this study, 10 opossums (Didelphis sp), had been used, already died and fixed, proceeding from the Department of Anatomy of USP and UNIFEOB. None animals were submitted to pain/suffering situations and their no life sacrifice. The pineal gland was found in all studied animals with and smaller dimention, not possessing, therefore goss features. By microscopy analysis we could found the gland in the correspondent space to median plan in relation to the encephalon, rostral and dorsally to the rostral coliculli, ventrally to the brain hemispheres and caudally to the habenular comissure. That consistes like an evagination of the diencephalons tectum showing the " $U$ " shape. Considering other pineal glands and its features in different species, we note the gland is extremely small for it specie, possessing dispersed secretory cells in the nervous parenchyma whose form, sufficiently irregular, suggests a small hormonal performance to them in the Didelphis genus. Comparativelly of the pineal gland feactures in different animals, the Didelphis genus, that was our aim, shows pecualirity as in size relation, only microscopically visible, than the fact to prossessing similar secretory cells also dispased in neighbor areas. All pecualiarites suggest refletion about the function action of the gland at the studied specie.
\end{abstract}

Key words:

Opossum. Pineal Gland. Animal

\section{Agradecimentos}

Ao Centro Universitário da Fundação de Ensino Octávio Bastos e à Universidade de São Paulo pela colaboração e apoio durante todas as etapas deste trabalho.

À CAPES pelo apoio financeiro que possibilitou a realização desta pesquisa.

\section{Referências}

1 GARTNER, L. P.; HIATT, J. L. Tratado de histologia. Rio de Janeiro: Guanabara Koogan, 1999. 426 p.
2 HOFER, H. O.; MERKER, G.; OKSCHE, A. Atypische formen des pinealorgans der Saugetiere. Verhandlungen der Anatomischen Gesellschaft. v. 70, n. 1, p. 97-102, 1976. 
3 TOLOSA, E. M. C. et al. Manual de técnicas para histologia normal e patológica. 2. ed. Barueri: Manole, 2003. 331 p.

4 JUNQUEIRA, L. C.; BIGNONAS, G.; BRETAN, R. R. Picrosirius staing plus polarizacion microscopy, a specifc method for collagen detection in the tissue sections. Histochem Journal, v. 11, n. 4, p. $447-$ 455,1979 .

5 INTERNATIONAL COMMITTEE ON VETERINARY GROSS ANATOMICAL NOMENCLATURA. Nomina anatomica veterinaria. 4. ed. Zurich, 1994. (Together with nomina histologica, 2. ed., 1992 and nomina embriologica veterinaria, 1992).

6 INTERNATIONAL COMMITTEE ON VETERINARY HISTOLOGICAL NOMENCLATURA. Nomina histologica. 2. ed. rev. Zurich, 1994. (Together with nomina anatomica veterinaria, 4 . ed. and nomina embriologica veterinaria.).

7 DYCE, K. M.; SACK, W. O.; WENSING, C. J. G. Tratado de anatomia veterinária. 2 . ed. Rio de Janeiro: Guanabara Koogan, 1998. 663 p.

8 SCHAFFER, E. A.; SYMINGTON, J.; BRYCE, T. H. Quain's elements of anatomy. New York: Longmans \& Green, 1909. $230 \mathrm{p}$.

9 VOLLRATH, L. Comparative morphology of the vertebrate pineal complex. The pineal gland including man. Progress in Brain Research, v. 42, n. 1 p. 25-38, 1979.

10 VOLLRATH, L. The pineal organ. Germany: Springer-Verlag, 1981. 665 p.

11 BRANCO, E. R. et al. Pesquisa anatômica da glândula pineal em capivaras (Hydrochoerus hydrochoeris). Brazilian Journal of Veterinary Research and Animal Science, v. 34, n. 4 p. 191-195,1997.

12 HOLANDA-BARROS, P. M. Estudo da pineal em jararacas (Bothrops jararaca) e cascavéis ( Crotalus durissus). 2002. 82 f. Dissertação (Mestrado em Ciências) - Faculdade de Medicina Veterinária e Zootecnia, Universidade de São Paulo, São Paulo, 2002.
13 SILVINO, M. J. et al. The pinealgland in adult"golden cutia"(Dasyprocta aguti, Rodentia Caviomorpha). Revista Chilena de Anatomia, v. 13, n. 1, p. 17-23, 1995.

14 CARVALHO, A. F. Histologia e Histometria da glândula da pineal de búfalos (Bubalus bubalisLinneaus, 1758). 1997. 117 f. Dissertação (Mestrado em Qualidade e Produtividade Animal) Faculdade de Medicina Zootecnia e Engenharia de Alimentos, Universidade de São Paulo, Pirassununga, 1997.

15 GOMES, L. A. Estudo morfológico da glândula pineal no cão. 2002. 80 f. Dissertação (Mestrado em Ciências) - Faculdade de Medicina Veterinária e Zootecnia, Universidade de São Paulo, São Paulo, 2003.

16 JORDAN, H. E. The microscopy anatomy of the epiphysis of the opossum. The Anatomy Record, v. 5, n. 7 , p. $325-338,1911$

17 BLIN, P. C.; MAURIN, C. Anatomie macroscopique de l'epiphyse des mammifères domestiques. Recueli Medicine Véterinaire, v. 1, n. 132, p. 36-52, 1956.

$18 \mathrm{OKSCHE}, \mathrm{A}$. Survey of the development and comparative morphology of the pineal organ. Progress in Brain Research, v. 10, n. 3 p. 3-29, 1965.

19 LEESON, C. R.; LEESON, T. S. Histologia. 3. ed. Rio de Janeiro: Interamericana, 1976. 533 p.

20 MOLLER, M.; BAERES, F. M. The anatomy and innervation of the mammalian pineal gland. Cell and Tissue Research, v. 309, n. 1, p. 139-150, 2001.

21 ROSS, M. H.; REITH, E. J.; ROMRELL, L. J. Histologia: texto e atlas. 2. ed. São Paulo: Panamericana, 1993. $779 \mathrm{p}$.

22 TULSI, R. S. A scanning electron microscope study of the pineal recessof the adulth brush-tailed possum (Trichosurus vulpeca). Journal Anatomy v.129, n. 3, p. 521-530, 1979

23 SAMARASINGLE, D.; DELAHUNT, B. The ependyma of the saccular pineal gland in the noneutherian mammal Trichosurus vulpeca. Cell and Tissue Research, v. 213, n. 3, p. 417-432, 1980. 
Braz. J. vet. Res. anim. Sci., São Paulo, v. 44, n. 3, p. 222-229, 2007 


\section{INSTRUÇÕES AOS AUTORES}

\section{Normas editoriais Artigo completo}

1 - Deve ser inédito e destinar-se exclusivamente ao periódico Brazilian Journal of Veterinary Research and Animal Science, sendo obrigatório anexar declaração assinada por todos os autores expressando concordância no pagamento de taxa como condicionante à sua publicação; 2 Limitar-se a um máximo de dez páginas digitadas, dentro da estrutura do item número cinco, não sendo contadas as páginas onde constem tabelas e ilustrações; 3 - Ser escrito em língua portuguesa, na ortografia oficial, ou em língua inglesa; 4 - Usar somente nomenclaturas oficiais e abreviaturas consagradas, não empregando abreviaturas no título do artigo; 5 - Ser estruturado dentro dos seguintes itens: a) Introdução; b) Materiais e Métodos; c) Resultados; d) Discussão; e) Conclusões; f) Referências; g) Resumo/ Palavras-chave; Abstract/Key-words. Os itens Resultados, Discussão Conclusões poderão ser colocados em uma única seção, salvo entendimento contrário da Comissão Científica; 6Apresentar, obrigatoriamente, dois resumos, nos idiomas inglês e português, não devendo ultrapassar 250 (duzentos e cinquenta) palavras, seguidos das palavras-chave, limitadas a cinco, que correspondem a palavras ou expressões que identificam o conteúdo do artigo.

Nota prévia

1 - Deve ser inédita e destinar-se exclusivamente ao periódico Brazilian Journal of Veterinary Research and Animal Science sendo obrigatório anexar declaração assinada por todos os autores expressando concordância no pagamento de taxa como condicionante à sua publicação, sendo obrigatório anexar declaração assinada por todos os autores expressando concordância no pagamento de taxa como condicionante à sua publicação; 2 - Limitar-se ao máximo de três páginas digitadas; 3 -Ser escrita em língua portuguesa, na ortografia oficial, ou em língua inglesa;

4 - Usar somente as nomenclaturas oficiais e abreviaturas consagradas; 5 Não devem ser subdivididos em seções separadas (Introdução, Materiais e Métodos etc.), mas devem apresentar, obrigatoriamente, dois resumos, com palavras-chave, à semelhança do que foi descrito para a apresentação de Artigo completo, além de referências. Os artigos de revisão só poderão ser publicados por especialistas de renome a convite da Comissão Editorial. Entretanto, o esboço de um artigo de revisão poderá ser submetido à Comissão Editorial sem prévia consulta e, se este for considerado apropriado, o(s) autor(es) será(ão) convidado(s) a preparar o artigo para publicação. Esses artigos devem seguir as normas de
Artigo completo, porém sem subdivisão em Introdução, Materiais e Métodos, Resultados e Discussão, preservandose apenas dois resumos, com palavraschave, à semelhança do que foi descrito para a apresentação de Artigo completo, além de referências.

\section{Apresentação dos trabalhos}

1 - Digitação: original em CD ou disquete de $31 / 2$ " de alta densidade, devidamente identificado com o título do artigo e nome do(s) autor(es) e três cópias impressas, inclusive suas tabelas e referências; deve ser digitado obrigatoriamente em formato A4 (21,0 29,7cm), espaço duplo, em uma só face de papel, margens de $2,5 \mathrm{~cm}$, fonte Times New Roman tamanho 10 e numeração consecutiva das páginas. Ilustrações e legendas devem ser relacionadas em folhas separadas. $O$ exto dos artigos deve ser apresentado utilizando-se o editor de texto Microsoft Word; 2 - Página de rosto: todo artigo eve ter uma página de rosto com título do artigo, nome(s) do(s) autor(es) e instituição de origem. O rodapé da página deve mencionar o endereço completo (inclusive e-mail) do autora quem deve ser encaminhado a correspondência. Observar que unicamente nesta página conste a identificação dos autores, para o devido sigilo e imparcialidade. Se o artigo for subvencionado, mencionar instituição que o patrocinou, assim como os agradecimentos; 3-Tabelas: devem ser numeradas em algarismos arábicos e encabeçadas pelo título, seguido de local e data. Na montagem das tabelas seguir: IBGE. Normas de apresentação tabular. 3. ed. Rio de Janeiro: IBGE, 1993. 61 p. O limite de abelas por trabalho é de cinco. Em casos excepcionais, conhecida a opinião da Comissão Científica, este úmero poderá ser ultrapassado. No texto devem ser indicadas pela palavra Tabela; 4 - Ilustrações (fotografias gráficos, desenhos ou esquemas): devem ser numeradas consecutivamente com algarismos arábicos e citadas como iguras. As fotografias devem ser identificadas somente com o titulo do artigo, além de conter no verso indicação de seu correto posicionamento. Fotos fornecidas em papel fotográfico devem ter ótima ré solução; e em CD ou disquete devem er extensão. TIF e resolução mínima de 300 dpi's. As legendas de ilustrações coloridas devem estar referenciadas somente por setas, símbolos e pontos quando publicadas em PB. Gráficos, desenhos ou esquemas devem ser fornecidos em CD ou disquete, impressos em folha à parte identificada somente com o título do artigo, além das respectivas legendas. Todas as ilustrações devem ser fornecidas em três vias. Os gráficos devem trazer sempre os valores numéricos que lhes deram origem. Desenhos e esquemas devem apresentar boa qualidade técnica e artística. Aceitar-se-á um número máximo de nove ilustrações por artigo ugerindo-se a seguinte distribuição: três fotografias, três gráficos e três desenhos/esquemas. Acima deste limite as despesas com reprodução correrão por conta do autor, ilustrações coloridas, independentemente do úmero, serão cobradas. No texto devem ser indicadas pela palavra Figura; 5 - Referências: devem seguir a mesma ordem numérica crescente utilizada no texto. Os títulos de periódicos devem ser mencionados de maneira uniforme, de preferência todos por extenso. Caso a opção seja pela abreviação dos títulos dos periódicos, consultar a NBR 6032. As referências seguem a normalização da NBR 6023/ 2002, que deve ser consultada para utros tipos de documentos não exemplificados nas Instruções aos Autores. Indicar os autores pelo sobrenome, em maiúsculas, seguido pelas iniciais do prenome, sendo separados por ponto-e-vírgula, seguido de espaço.

Exemplos:

BONAGURAJ. D. [...] (1 autor)

AANTOS, J. A.; MELLO, M. R. [...] (2 autores)

BENNETT, B. T.; ABEE, C. R.;

HENRICKSON, R. [...] (3 autores)

VILELA, D.; MARTINS, C. E.;

BRESSAN, M.; CARVALHO, L. A. [...

(4 autores ou mais) ou VILELA, D. et

al. [...].

Exemplo de periódico

KOTZEKIDOV, P.; BLOUKAS, J. G.

Effect of protective cultures and

packaging film permeatibility on shelfife of sliced vacuum-pocked cooked ham.MeatScience, v.42,n.3,p.333

\section{5, 1996 .}

Exemplo de livro no todo

HALLIWELL, R. E. W. GORMAN, N.

T. Veterinary clinical immunology.

London: W. B. Saunders, 1989. 548 p.

Exemplo de autor diferente para o livro e capítulo

FENNER, W. R. Avaliação neurológica

os pacientes. In: ETTINGER, S.j.

Tratado de medicina interna

veterinária. 3. ed. São Paulo: Manole

992. p. 577-606.

xemplo de mesmo autor para o livro e capítulo

HORTON, H. Deleterius changes in meat. In: THORTON, H. Aspects of

meat inspection. London: Thindall \& Cassel, 1973. p. 63-72.

xemplo de tese

BIRGEL, E. H. Estudo do quadro eritrocitário de caprinos (Capra hircus,

) normais criados no Estado de São

Paulo: influências de fatores raciais

sexuais, etários e alimentares, 1973.92

Medicina Veterinária e Zootecnia,

Universidade de São Paulo, São Paul

xemplo de evento

OLIVEIRA, C. A. Hormonoterapia em

cadelas e gatas. In: CONGRESSO

BRASILEIRO DE REPRODUÇÃO

, 1991, Belo Horizonte.

Anais... Belo Horizonte: Colégio

Brasileiro de Reprodução Animal, 1991.

p. 100-111.

Exemplo de monografia eletrônica

considerada no todo

AUTORIA. Título. Edição. Local de publicação: Editora, ano de publicação.

Tipo de suporte, Características do uporte, Produtor, data de citação, isponibilidade e Acesso).

Online

POORE, M. H. Alternative feeds for eef cattle. North Carolina: North Carolina Corporative Extension Service, 1994. Disponível em: <http:// ww.ces.ncsu.edu/drought/dro28.html>.Acesso em: 23abr. 1997. Exemplos de artigos de periódicos etrônicos

AUTORIA. TÍTULO DO ARTIGO. Título do periódico, volume, fascículo (número), páginas, ano de publicação. (Tipo de suporte. Características do suporte, Produtor, data de citação, Disponibilidade e acesso).

Online

MENDONÇA JR., C.X,; MARTINS, A.P.; MORI, A.V.; SILVA, A.B.; MORI, C.S. Efeito da adição de óleo de peixe à dieta sobre o desempenho e níveis de ípides plasmáticos e de colesterol no ovo de galinhas poedeiras. Brazilian journal of Vetennary Research and Animal Science, v.37, n.1, 2000. Disponível em: <http://www.scielo.br/ cgi_bin/wxis.exe/iach/scielo > . Acesso em: 31 jan. 2001

6 - Citações: devem ser feitas por numeração única e consecutiva em sobrescrito, utilizando-se algarismos arábicos, remetendo à lista de referências na mesma ordem em que aparecem no texto. Quando indispensável para a compreensão do texto, combinar o(s) sobre nome(s)do(s) autor(es) com a indicação do número sobrescrito correspondente ao número que aparece nas referências. Neste caso, a citação será pelo sobrenome de cada autor, ou pelo nome da entidade responsável até o primeiro sinal de pontuação que aparece na respectiva referência. Quando se tratar de três autores, todos devem ser citados. No caso de mais de três autores, a citação deve ser acompanhada pelo sobrenome do primeiro autor seguido da expressão e tal. (s/ itálico), em letra maiúscula e minúscula Se a citação estiver inserida no texto utilizar letras maiúsculas e minúsculas; se estiver entre parênteses utilizar somente letras maiúsculas. Exemplos:

Segundo Yanaguita ${ }^{9}[. .$. 